\title{
ESCOLA PÚBLICA E CLASSES SOCIAIS EM MARX: ALGUNS APONTAMENTOS ${ }^{1}$
}

João Carlos da Silva ${ }^{2}$

\section{RESUMO:}

Este artigo é resultado das leituras e reflexões realizadas no grupo de estudo sobre as obras de Marx e Engels, como parte das atividades desenvolvidas no interior do grupo de pesquisa HISTEDOPR- GT, Cascavel, PR. Em linhas gerais discutimos alguns elementos constitutivos da relação entre educação e classes sociais. O tema das classes sociais está no centro da concepção marxista ao fornecer ferramentas para compreender, a sociedade capitalista, em sua totalidade plena de contradições. Conclui que a globalização financeira significou a mundialização da crise, a partir do tensionamento na relação capital trabalho. A burguesia como classe hegemônica não consegue expressar projeto de superação do estado atual, ao mesmo tempo em que se coloca como classe destrutiva gerando violência, miséria social e cultural. Procuramos neste sentido contribuir com o debate acerca da temática em tela.

Palavras-chave: Educação, classes sociais, alienação, ideologia

\section{PUBLIC SCHOOL AND SOCIAL CLASSES IN MARX: SOME NOTES}

\section{ABSTRACT:}

This article is resulted of the readings and reflections carried through in the group of study on the workmanships of Marx and Engels, as part of the activities developed in the interior of the group of research HISTEDOPR- GT, Cascavel, PR. In general lines we argue some constituent elements of the relation between social education and classrooms. The subject of the social classes is in the center of the marxist conception to the one in supplying tools to them to understand, the capitalist society, in its full totality of contradictions. It concludes that the financial globalization meant the world of the crisis, from the tensioning in the capital relation work. The bourgeos as hegemonic social classes does not obtain to express project of overcoming of the current state, at the same time where if she places as destructive classes generating violence, social and cultural misery. We look for in this direction to contribute with the debate concerning the thematic one in screen.

Keywords: Education, social classes, alienation, ideology

\section{Introdução}

Em conferência proferida aos educadores brasileiros, em 2006, o historiador italiano, Mario Aliguiero Manacorda lançou uma perspectiva pouco animadora: o aprofundamento das contradições e dos conflitos sociais, como fenômeno do século XXI. Que as condições de vida se degradaram nos últimos anos, já não é mais nenhuma novidade. Esta degradação não é exclusiva nos educadores, mas está presente no conjunto dos trabalhadores do setor público e privado. Entender as transformações por que passa a humanidade na atualidade, é certamente um desafio, mas também é uma primeira condição no sentido de transformá-la. 
Analisar as classes sociais e a revolução requer considerações acerca do próprio conceito de classe, suas relações entre as determinações econômicas, políticas e ideológicas, bem como as transformações na estrutura de classes. Este artigo é resultado das reflexões desenvolvidas no interior do grupo pesquisa HISTEDOPR-GT, Cascavel, $\mathrm{PR}^{3}$ Procuramos discutir e contribuir com o debate acerca a relação entre educação e classes sociais, enquanto constituição histórica.

\section{Educação e classes sociais}

Os ideais da escola pública universal gratuita e laica, não são novos. Suas raízes estão ligadas ao passado, mais propriamente ao século XVIII, na França, por ocasião da ascensão da burguesia, enquanto classe revolucionária, que naquele momento, lutava contra o mundo feudal.

O discurso liberal, produzido historicamente, tornou-se o princípio norteador da nova organização social. Com a Revolução Francesa e a tomada do poder político pela burguesia, urgia construir um sistema de ensino, voltado para formar os novos homens, ou seja, os futuros cidadãos. A escola burguesa, estruturada dentro dos princípios de liberdade, igualdade, em defesa da propriedade e da democracia, foi resultado do modo de produção capitalista, que, nesse momento histórico, estavam sendo colocados a todos.

A discussão sobre classe social surge em Marx, concomitantemente a sua analise sobre o processo de produção e circulação do capital. Centrou suas investigações acerca da origem, do desenvolvimento e da organização da ordem capitalista. Nos Manuscritos econômico-filosóficos ao analisar, as condições de existência do operário, aponta o fator econômico, como aspecto principal:

O trabalhador torna-se tanto mais pobre quanto mais riqueza produz, quanto mais a sua produção aumenta em poder e extensão. $\mathrm{O}$ trabalhador torna-se uma mercadoria tanto mais barata, quanto maior número de bens produz. Com a valorização do mundo das coisas, aumenta em proporção direta a desvalorização do mundo dos homens. $\mathrm{O}$ trabalho não produz apenas mercadoria; produz-se também a si mesmo e ao trabalhador como uma mercadoria, e justamente na mesma proporção com que produz bens (MARX, 2002, p. 111).

Com o desenvolvimento industrial, temos a divisão cada vez mais evidente da sociedade em duas classes principais: a burguesia, proprietária dos meios de produção, classe cada vez mais Abastada e o proletariado, classe cada vez mais pobre e miserável, cuja força de trabalho é a única propriedade. O homem, EM não sendo o fim da economia burguesa, mas um mero instrumento de produção é tratado como máquina, submetido às relações sociais opressoras, alienando-o da verdadeira essência humana.

No final do século XIX, a escola torna-se pública, laica e obrigatória de maneira efetiva, cabendo a ela exercer o papel de preservar as relações burguesas. No Manifesto do Partido Comunista, Marx refere-se a uma classe intermediária, denominada classe média, não proprietária, mas simpática às bandeiras da burguesia.

As classes médias - pequenos comerciantes, pequenos fabricantes, artesãos, camponeses - combatem a burguesia porque esta compromete sua existência como classes médias. Não são, pois, revolucionárias, mas conservadoras; mais ainda, são reacionárias, pois pretendem fazer girar para trás a roda da história. Quando são revolucionárias é em consequência de sua eminente passagem para o proletariado; não defendem então seus interesses atuais, mas seus interesses futuros; 
abandonam seu próprio ponto de vista para se colocar no do proletariado (MARX, 1998, p. 29).

O conflito entre elas se explicita como uma verdadeira "guerra ininterrupta, ora franca, ora disfarçada" (op.cit. p. 22). Com o acirramento dos conflitos, por conta da Revolução Francesa, o embate entre as classes, torna-se mais nítidos, entre a nobreza feudal e a burguesia em ascensão, que impunha uma nova concepção de Estado e sociedade. No século XIX a questão das classes sociais, tornou-se objeto de preocupação dos debates teóricos. Ao afirmar que a luta de classes era motor da história, Marx elucidava a verdadeira força que rege a história. Engels no prefácio, em $O 18$ Brumário de Luis Bonaparte diz:

\begin{abstract}
Fora precisamente Marx quem primeiramente descobriu a grande lei da marcha da história, a lei segundo a qual todas as lutas históricas, quer se processem no domínio político, no religioso, no filosófico ou qualquer outro campo ideológico, são na realidade, apenas a expressão, mais ou menos clara, de lutas entre classes sociais, e que a existência, e, portanto, também os conflitos entre essas classes,são por seu turno condicionados, pelo grau de desenvolvimento de sua situação econômica, pelo seu modo de sua produção e pelo seu modo de troca, este determinado pelo precedente. Essa lei - que tem para a história a mesma importância que a lei da transformação da energia tem para as ciências naturais (...) (MARX \& ENGELS, 1980, p.202).
\end{abstract}

A questão das classes sociais aparece em Marx, em uma dimensão científica, atribuindo-lhe o papel básico ao longo da história, desmistificando aquelas análises da economia política, sobretudo em relação às classes, no conjunto da organização da produção capitalista ${ }^{4}$. No campo ideológico temos a luta entre as ideias da classe burguesa e da classe proletária, mediante a clássica premissa de que as ideias dominantes são as ideias da classe dominante. Neste cenário, a luta ideológica é uma das lutas a serem enfrentadas:

\begin{abstract}
Os pensamentos da classe dominante são também, em todas as épocas, os pensamentos dominantes; em outras palavras, a classe que é o poder material dominante numa determinada sociedade é também o poder espiritual dominante. A classe que dispõe dos meios da produção material dispõe também dos meios de produção intelectual, de tal modo que o pensamento daqueles aos quais são negados os meios de produção intelectual está submetido também à classe dominante. Os pensamentos dominantes nada mais são do que a expressão das relações materiais dominantes concebidas sob a forma de ideias e, portanto, a expressão das relações que fazem de uma classe a classe dominante; dizendo de outro modo, são as ideias de seu domínio (MARX \& ENGELS, 1984, p.48).
\end{abstract}

Marx faz a crítica da concepção burguesa do Estado que começa logo após a Revolução Francesa. O Estado, em sendo um braço da classe dominante, a única ação política realmente legítima é aquela que conduz à eliminação da política e do Estado. Marx reduz o conceito "Estado" a um simples reflexo econômico. A crítica do Estado aparece também na crítica à filosofia do Estado de Hegel, quando esta é entendida como justificação do Estado capitalista. 
Para que coincidam a revolução de um povo e a emancipação de uma classe especial da sociedade burguesa, para que uma classe valha por toda a sociedade, é necessário, pelo contrário, que todos os defeitos da sociedade se condensem numa classe, que uma determinada classe resuma em si a repulsa geral, que seja a incorporação do obstáculo geral; é necessário, para isto, que uma determinada esfera social seja considerada como crime notório de toda a sociedade, de tal modo que a emancipação desta esfera surja como autoemancipação geral (MARX, 1984, p. 8).

\section{A alienação, educação e classes sociais}

Marx ao desenvolver sua análise sobre a dinâmica do capitalismo abordou sob a perspectiva de sua natureza filosófica ao falar da "alienação", do "fetichismo da mercadoria" e da "reificação". O capitalismo produz a alienação do homem afastando-se de si mesmo e dos outros homens na medida em que seu corpo, seu espírito, e seus amigos lhe são afastados. As mercadorias não lhes aparecem como objetos feitos por eles, mas sim na forma de mercadoria ${ }^{5}$, como algo estranho.

Kosik em Dialética do concreto denomina este fenômeno como pseudoconcreticidade, fenômeno ao mostrar parcialmente a realidade, escondendo nela, uma essência a ser desvendada, portanto "[...] pesquisar o fenômeno é desvendar a essência oculta" (1986, p.13). A relação entre os homens produtores, que se estabelece no "capitalismo", resume-se em uma relação social entre produtores. Tal relação não aparece dessa forma, mas é vista como uma relação em que os produtores não existem e a relação se dá entre os produtos de seus trabalhos. Nesta relação entre coisas, aparece aos olhos de todos como "entes", onde cada produto do trabalho humano é fetichizado, ganha vida e se põe diante do seu realizador.

Marx discute a alienação como o fato econômico principal de sua época, a partir da seguinte premissa: $\mathrm{O}$ trabalhador torna-se tanto mais pobre quanto mais riqueza produz, quanto mais a sua produção aumenta em poder e extensão. $O$ trabalhador torna-se uma mercadoria tanto mais barata, quanto maior número de bens que produz. Com a valorização do mundo das coisas, aumenta em proporção direta a desvalorização do mundo dos homens (MARX, 2002, p.111).

A alienação em Marx é entendida como relação contraditória do trabalhador com o produto de seu trabalho e a relação do trabalhador ao ato de produção, um processo de objetivação, torna o homem estranho a si mesmo, aos outros homens e ao ambiente em que vive: "A apropriação surge como alienação, e a alienação como apropriação" (Idem, p.122). Ele não pertence à natureza, aos deuses, mas a alguém distinto do trabalhador, ou seja, ao capitalista. O trabalhador ao fabricar uma mercadoria, ele se torna uma, reduzindoo em instrumento de riqueza de outros homens.

Snyders em Escola, classe e luta de classes, publicado pela primeira vez em 1977, assevera que na sociedade de classes, a função principal da escola é a inculcação da ideologia burguesa e a sujeição e o disfarce da ideologia proletária, para impedir o desenvolvimento da ideologia do proletariado revolucionária, pois ela qualifica o trabalho intelectual e desqualifica o trabalho manual, sujeitando o proletariado à ideologia burguesa sob um disfarce pequeno burguês. "O papel da escola, a função real e oculta que lhe é destinada, é precisamente esta: a partir dos fracassos dos desfavorecidos, mergulhá-los na humilhação para que não renunciem a uma atitude de humildade" (SNYDERS, 1981, p. $71)$. 
O homem, ao produzir mercadorias, ele mesmo se torna uma mercadoria, reduzindo-o a uma coisa. Concordando com a economia política, reafirma o trabalho como fundamento de toda a riqueza e de toda a propriedade, porém se realiza na sua forma alienada, isto é, no regime da propriedade privada. A alienação do trabalho é considerada como a mãe de todas as outras alienações cabendo ao homem passar do entendimento de alienação para o entendimento de práxis.

O trabalhador põe a sua vida no objeto, porém, ele já não lhe pertence mas sim ao objeto. Quanto maior a sua atividade, mais o trabalhador se encontra objeto. Assim, quanto maior é o produto, mais ele fica diminuído. Quanto mais valor o trabalhador cria, mais sem valor e mais desprezível se ele torna. Quanto mais refinado é o produto mais desfigurado é o trabalhador.

A divisão do trabalho, no interior da produção capitalista, ao separar o trabalho manual do trabalho intelectual, condicionou todas as suas contradições, como o acesso ao trabalho assalariado, tempo livre e a um tipo de educação específico. Outra consequência do capitalismo é separar a arte da técnica, abstraindo-a cada vez mais da produção coletiva, para dela fazer uma questão individual.

Nas condições da economia capitalista, a troca de mercadorias consiste no fenômeno mais banal e elementar, cuja produção é realizada em circunstâncias tão alienadoras que o trabalho e a atividade criativa do homem torna-se um processo de desumanização. Para Kosik (1998, p. 78) o homem vive constantemente entre a autenticidade e a não-autenticidade, devendo haver cotidianamente um esforço intelectual para libertar-se de uma existência que não lhe pertence, mas que lhe é imposta pelas relações de produção.

As limitações intelectuais da classe operária foram impostas pelas condições do trabalho industrial, exigindo um componente subversivo para que o trabalhador, no interior das contradições da ordem burguesa, alcance sua consciência. O desenvolvimento intelectual de classe é a consequência direta da situação econômica do operário, e esta é das mais complexas, porque evolui nas contradições, nos altos e baixos dos ciclos de crise e de prosperidade, com fases revolucionárias ou contra-revolucionárias.

A grande indústria amadureceu e acirrou as contradições e antagonismos da forma capitalista do processo de produção, ou seja, ao mesmo tempo em que os elementos, de formação e de consciência, os elementos subversivos da velha sociedade. A educação burguesa ignora a sensibilidade do aluno, interessada exclusivamente pelas suas capacidades de produção, impondo a ela uma concepção do trabalho produtivo.

Marx afirma que a educação deve partir da prática e da sensibilidade própria da criança, «os sentidos práticos, e sobretudo o nariz e a boca, sendo os primeiros órgãos com os quais a criança julga o mundo», não faz mais do que retomar a crítica de Fourier a qualquer ensino da «civilização»: «A escola-coloca a teoria antes da prática. Todos os sistemas civilizados caem neste erro: não sabendo seduzir a criança para o trabalho, são obrigados a deixá-la em férias até aos 6 ou 7 anos, idade que ela deveria ter utilizado para se tornar um hábil prático; depois, aos 7 anos, querem iniciá-la na teoria, nos estudos, em conhecimentos cujo desejo ninguém nela despertou (MARX \& ENGEL, 1978, p.37).

No interior da sociedade capitalista a burocracia tornou-se instrumento de dominação das classes exploradas, em que o pensar e o decidir são privilégios de um grupo. A burocracia visa controlar o trabalho e as formas de pensar, cuja característica principal é o segredo, o mistério como uma atividade fechada. Idolatra a autoridade e exalta regras rígidas, conservando tradições. 


\begin{abstract}
A burocracia é um círculo de que ninguém pode sair. A sua hierarquia é a do saber. A cabeça confia às esferas inferiores o cuidado de conhecer o detalhe, em troca do que as esferas inferiores cedem à cúpula a inteligência do geral - e ambos fazem assim mutuamente a troca. A burocracia é o Estado imaginário que flanqueia o Estado real, é o espiritualismo do Estado. Todas as coisas obtêm assim um duplo significado - um real, o outro burocrático. O mesmo se passa com a vontade, por exemplo. $\mathrm{O}$ que é real é conseqüentemente tratado burocraticamente, ou seja, como uma coisa espiritual, do além. A burocracia tem na sua posse o Estado, o ser espiritual da sociedade: é a sua propriedade privada (MARX \& ENGELS, 1978, P. 58).
\end{abstract}

A vida no trabalho se torna, para ele, apenas o meio que lhe permite existir. Em outros termos, o sujeito humano se torna o objeto de seus próprios produtos. Marx acusa a economia política de ser a ciência da riqueza, da renúncia, da privação do ar puro, “[...] comer, beber, comprar livros, ir ao teatro, ou ao baile, ao bar, quanto menos cada um pensar, amar, teorizar, cantar, pintar, poetar, etc" (idem , p.151).

Nesta passagem verificamos as origens da escola burguesa, em seu aspecto economicista da educação e do indivíduo:

Muitos rapazes que frequientaram a escola durante as 150 horas prescritas, encontram-se exactamente no mesmo estado, ao cabo de 6 meses da sua estadia na fábrica, do que no ponto de partida; esqueceram naturalmente tudo o que tinham aprendido antes. Noutras empresas de estampagem sobre algodão, a freqüência da escola depende totalmente das exigências do trabalho na empresa. O número de horas obrigatórias é aí satisfeito em cada período de 6 meses por prestações de 3 a 4 horas de cada vez, disseminadas por todo o semestre. A criança, por exemplo, vai à escola um dia das 8 às 11 da manhã, outro dia da 1 às 4 da tarde, depois durante toda uma série de dias para aí voltar em seguida das 3 às 6 horas da tarde durante 3 ou 4 dias seguidos ou durante uma semana. Desaparece de novo três semanas ou um mês, depois volta durante algumas horas em certos dias de folga, quando por acaso o patrão não precisa dela. A criança passa assim da escola para a fábrica e da fábrica para a escola, até que se atinja o total das 150 horas (Idem, p.68).

Marx argumenta que é da natureza do homem produzir objetos nos quais ele se reflete, porém esses objetos são tomados pela lógica da produção vigente. Ele é incapaz de ser dono do produto de seu trabalho, e se torna estranho à sua própria criação, que o enfrenta como algo hostil e alheio. Essa alienação do homem em relação aquilo que produz também implica a sua alienação em relação aos outros homens:

É assim que os operários são postos à parte e desprezados pela classe no poder no plano moral, como o são nos planos físico e intelectual. O único interesse que ainda se tem por eles manisfesta-se pela lei, que lhes deita a mão assim que se aproximam demasiado da burguesia; tal como para com os animais despidos de razão, só se utiliza com eles um único meio de educação: o chicote, a força brutal que não convence, mas que só intimida (Idem, pp.70-71).

Marx nos alerta que a escola contemporânea tem a imagem e semelhança da ordem burguesa, servindo a seus propósitos econômicos, políticos, ideológicos e culturais. A 
burguesia, de classe revolucionária, ao instalar-se no poder, tornou-se classe conservadora, servindo-se do instrumento educacional, ou seja, do processo ideológico, como forma de manter-se no poder e difundir seu mundo como se fosse o mundo de todos:

A tese que aqui se impõe, é que, tendo a burguesia sido em primeiro lugar revolucionária, tornando-se depois conservadora e finalmente contrarevolucionária, a sua direcção da produção e do Estado, bem como a sua justiça, a sua ciência e as suas belas-artes, foram úteis e progressivas no início, e em seguida degeneraram. (pp.10-11).

Em Gramsci, a divisão da sociedade em classes também se explicita pela "divisão fundamental da escola em clássica e profissional "[...] a escola profissional destinava-se ás classes instrumentais, ao passo que a clássica destinava-se as classes dominantes e aos intelectuais" (1991, p, 118). Como superação Gramsci propõe uma "[...] escola unitária ou de formação humanista (entendido esse termo, "humanismo", em sentido amplo e não apenas em sentido tradicional) ou de cultura geral deveria se propor a tarefa de inserir os jovens na atividade social, depois de tê-los levado a um certo grau de maturidade e capacidade, à criação intelectual e prática e a uma certa autonomia na orientação e na iniciativa" (Idem, p, 121).

Snyders seguindo a tradição marxista enfatiza que a escola é palco da luta de classes, e por isto deve ser utilizada pelas classes exploradas, pelas forças progressistas, como um dos seus instrumentos de luta e de libertação. A rigor a escola está apenas a serviço da classe dominante, com isso o sistema de ensino contribui para perpetuar a estrutura das relações de classe e ao mesmo tempo para legitimá-la6.

O fracasso ou mesmo a fraqueza do sistema de ensino é resultado do papel que a escola historicamente desempenhou, mascarando a relação entre a origem social e os resultados escolares. A escola foi uma das primeiras instituições a realizar esta divisão entre os que sabem ler e os que não sabem, essa divisão da escola primária vai refletir nas divisões do futuro, na divisão entre as classes sociais. $O$ sistema educacional, meritocrático e elitista por excelência, sustentou-se sobre o mito de igualdade de condições entre os alunos. O mito da meritocracia consiste em que, as crianças enxerguem a si próprias como responsáveis pelo papel social que irão cumprir a partir de seus fracassos escolares é aí que se habituam as crianças a estarem separadas em grupos de acordo com sua classe social.

Alguns terão que ler e escrever, outros precisarão de conhecimentos técnicos sobre as máquinas que irão operar nas indústrias. Desse modo, foi necessário à burguesia universalizar o acesso à educação e dividir o grau de instrução que cada camada do proletariado receberá de acordo com as necessidades impostas pela divisão social do trabalho e pelos processos produtivos.

Neste sentido o desafio é construir uma pedagogia que leve o aluno a um conhecimento verdadeiro, científico, que the possibilite uma formação e posse do conhecimento acumulado pela humanidade e, assim, possa participar das lutas de seu tempo, possa contribuir para a transformação da sociedade. E isto só pode ser feito se o conteúdo, o saber escolar, estiver em continuidade com a realidade dos alunos e ao mesmo tempo lhes forneça elementos para uma ruptura com a ideologia dominante.

Althusser, Bordieu-Passeron, Establet e Giroux ao discutiem a escola como aparelho reprodutor e transmissor da ideologia hegemônica, entendiam esta como sendo conjunto de valores, concepção de sociedade e ideias da classe dominante. Louis Althusser (1971) em Aparelhos Ideológicos de Estado suscitou amplos debates acerca do papel da escola na sociedade burguesa, no final dos anos 1970, produzindo importante 
impacto no pensamento educacional brasileiro, acerca da escola pública e seu papel na sociedade.

\section{Considerações finais}

A escola desde a modernidade no processo de expansão foi colocada para diferentes finalidades, religiosa, em Comenius, econômica, em Smith e civil em Rousseau. Após o século XIX, a escola pública passou a assumir um discurso conservador de acordo com os interesses político-ideológicos da burguesia. Na pratica a burguesia reduziu a educação a um valor econômico, visando exclusivamente à formação da força de trabalho, recortando o homem em sua humanidade, ao reduzi-lo a uma mercadoria e instrumento de trabalho. Os investimentos na educação quando este acontece visa um retorno imediato, fazendo da educação e do conhecimento transmitido em capital a ser investido.

Ao se falar em qualidade em educação é preciso perceber que está qualidade não é neutra, está vinculada aos interesses hegemônicos. Daí a importância do posicionamento do educador, na definição desses critérios.

A criação de diversos organismos internacionais como: ONU, FMI, OIC e o BID, ao longo do século XX, foi uma expressão da forma de internacionalização do capital, que prevaleceu neste período que relacionava sistemas econômicos, a partir de poderes políticos nacionais ou plurinacionais. Visava, sobretudo, regulamentar políticas macroeconômicas e programas de reconstrução dos países pobres, visando construir uma estabilidade necessária para a livre circulação de capital. Para além de adotar políticas econômicas aos países pobres, visava controlar governos, enfim a vida de todos os povos. Os mecanismos de controle econômicos tomam formas cada vez mais complexas e eficientes de dominação cultural, e de conservação da sociedade da mercadoria.

Conforme Mészáros (2005) a educação na sociedade capitalista há muito deixou de ter a característica de libertação e emancipação humana, mas é uma mercadoria que está a serviço do capital. Conforme esse autor, a educação formal tem a finalidade de produzir o conformismo e a aceitação dos indivíduos a sua condição de classe, ou ocupação na esfera produtiva da sociedade. A educação formal é para esse autor uma forma de produção de homens (mão de obra) e de conhecimento para a máquina produtiva, além de produzir a internalização dos valores burgueses mercadológicos e conformistas.

A burguesia ao instalar-se no poder, passou a assumir uma natureza destrutiva do homem e da sociedade. As crises cíclicas pelos quais o capital vem passando desde o século XX, crises cada vez mais amplas, agressivas e destrutivas presentes em todas as instâncias da sociedade, no econômico, cultural, social e no meio ambiente. A globalização financeira significou a mundialização da crise, na medida em que a burguesia não expressa mais projeto de superação do estado atual, ao mesmo tempo em busca destruir qualquer iniciativa ou alternativa de sua superação gerando subdesenvolvimento e produzindo violência, miséria social e cultural. Apesar deste cenário, existe vida inteligente para além do mundo do capital.

Urge forjar uma escola para a emancipação e não para a alienação, uma escola sobre o trabalho e não para o trabalho. Uma escola única para todos inicial de cultura geral, humanista, formativa, voltada ao desenvolvimento cientifico e cultural, mediante o rebaixamento dos espaços formativos, entre eles a escola publica. Parafraseando Mészáros, a partir de José Martí: os remédios não podem ser formais, mas devem ser essenciais.

\section{Bibliografia}

ENGELS, F. Do socialismo utópico ao socialismo científico. São Paulo: Global, 1998.

CHESNAY, François. A mundialização do capital. São Paulo: Xamã, 1996. 
LÊNIN. V. Que Fazer? SP: Hucitec, 1986.

MARX, Karl. Manuscritos econômico-filosóficos. São Paulo: Martin Claret, 2002. (Col. A obra prima de cada autor)

O Capital. VI. São Paulo: Difel, 1985.

Para a Crítica da Economia Política do Capital: o rendimento e suas fontes. São

Paulo: Nova Cultural, 2000. (Col. Os Pensadores)

A ideologia Alemã V.1. São Paulo, Martins Fontes, 1984.

A ideologia Alemã: Teses sobre Feuerbach. SP: Moraes, 1984.

O 18 Brumário de Luís Bonaparte. In: Obras Escolhidas V1. Alfa Omega.

Manifesto do Partido Comunista. In. Obras escolhidas. V.1. SP: Alfa Omega

As lutas de classes na França de 1848 a 1850. In. Obras escolhidas. V.1. SP: Alfa

Omega.

MARX \& ENGELS. Crítica da educação e do ensino. Introdução e notas de Roger Dangeville. Lisboa - Portugal: Moraes Editores, 1978.

MARX \& ENGELS. Manifesto do Partido Comunista. Prólogo de José Paulo Neto: São Paulo: Cortez, 1998.

Introdução à crítica da filosofia do Direito de Hegel. In. Obras escolhidas. V.1 . SP: Alfa Omega.

GRAMSCI, A. Os Intelectuais e a Organização da Cultura. Tradução: Carlos Nelson Coutinho. Editora Civilização Brasileira S.A. Rio de Janeiro-RJ, 8 a edição, 1991

SNYDERS, George. Escola, classe e luta de classes. 2. ed. Portugal, Lisboa: Moraes, 1981.

\section{Notas}

${ }^{I}$ Este artigo é resultado das reflexões desenvolvidas no interior do grupo de pesquisa HISTEDBR- GT, Cascavel, PR. O grupo de estudo é uma das atividades desenvolvidas desde 2003, pelo grupo HISTEDOPRRegião Oeste do Paraná. Neste período foram realizadas leituras de textos por Marx e Engels, bem como de autores inseridos na tradição marxista como István Mészáros e Dermeval Saviani. Como forma de homenagear Karl Marx no transcurso dos 122 anos de seu falecimento e de demonstrar a atualidade e o caráter revolucionário de sua teoria, o Grupo de Pesquisa promoveu encontros de estudo sobre as principais obras de Marx e Engels. Inicialmente foi discutida a Biografia de Karl Marx e Friedrich Engels, em seguida foram feitas leituras e discussões de alguns textos entre eles: O Capital, Contribuição à Crítica da Economia Política - Marx - (1859); Formações Econômicas Pré-capitalistas - Marx - (1848); Miséria da Filosofia Marx - (1847); Introdução à crítica da filosofia do Direito de Hegel; Teses sobre Feuerbach; A situação da classe trabalhadora na Inglaterra; Ideologia Alemã - Marx/Engels - (1846); Manuscritos econômicofilosóficos; Manifesto do Partido Comunista - Marx/Engels - (1848); A questão Judaica e Discurso diante do túmulo de Marx, 1883. Tínhamos como objetivos realizar estudo sistemático da obra de Marx e Engels; Compreender a obra Marxiana em seu contexto histórico, social, político e econômico; Aprofundar os conhecimentos sobre o materialismo histórico e dialético; Verificar o caráter revolucionário da teoria Marx. Como procedimento metodológico as atividades foram desenvolvidas na forma de grupos de estudo, os textos eram disponibilizados previamente, de modo que os participantes possam lê-los com antecedência, possibilitando, assim, maior debate, aprofundamento e enriquecimento nas discussões.

${ }^{2}$ Doutor em História e filosofia da Educação/FE-UNICAMP. Professor no Colegiado do Curso de Pedagogia/UNIOESTE, Cascavel, PR Membro do Grupo de pesquisa HISTEDBR/GT-Cascavel. E-mail: jcsilva05@terra.com.br

${ }^{3}$ O HISTEDOPR foi criado em 2002, se organiza, cresce e estrutura-se a partir de 2003, quando o Prof. Dr. Paulino José Orso assume a coordenação, integrando outros docentes e discentes do Curso de Pedagogia da Unioeste/Cascavel, alunos da Pós-graduação, além de professores da Rede Estadual e Municipal de ensino. O grupo de pesquisa surgiu tendo como objetivo levantar, catalogar e digitalizar as fontes referentes à história da educação na região Oeste do Paraná. Enquanto GT, está vinculado ao Grupo de Pesquisa em "História, Sociedade e Educação no Brasil" - HISTEDBR - que tem abrangência nacional e organiza-se por meio de Grupos de Trabalho (GTs) regionais. O HISTEDOPR tem como um de seus principais objetivos, promoverem o "Levantamento, a Organização e a Catalogação de Fontes Primárias e Secundárias para a 
História da Educação na Região Oeste do Paraná", contribuindo assim, com os demais grupos que integram o HISTEDBR, para ampliar o levantamento, a organização e a catalogação das fontes em âmbito nacional. Por um lado, isto se faz necessário em função da carência da historiografia educacional na Região Oeste do Paraná e, por outro, tendo em vista que se as fontes historiográficas não forem preservadas e catalogadas, futuramente não teremos nem fontes nem História e continuaremos sem a possibilidade construir algo novo e diferente em decorrência de não podermos conhecer nosso passado.

${ }^{4}$ Marx, defini as classes a partir das relações de produção. A consciência de classe também se insere na condição em que cada classe na produção social. No interior da sociedade burguesa, a luta de classes é travada como uma luta que se realiza no campo econômica, na estrutura econômica, ideológica, na estrutura ideológica, e política na estrutura política. Lênin em Que Fazer? considera que esta luta é também uma luta profissional, porque as condições de trabalho são extremamente variadas, de acordo com as profissões e, portanto, a luta pela melhoria de suas condições deve ser forçosamente, conduzida pela profissão “(...) (1986, p.48-49)"

${ }^{5}$ No mercado elas ganham vida própria, e eles, os trabalhadores, se tornam objetos que seguem as regras do mercado. Se não as consumirem não existem, são "excluídos do mercado". Segundo a noção marxista de realidade concreta, a realidade das coisas não se apresenta imediatamente ao homem tal qual elas são. $\mathrm{O}$ trabalho se torna não a satisfação de uma necessidade, mas apenas o meio para a satisfação de outras necessidades. A vida do trabalhador se torna, para ele, apenas o meio que lhe permite existir. Em outras palavras, o sujeito humano se torna o objeto de seus próprios produtos. O trabalho se torna não a satisfação de uma necessidade, mas apenas o meio para a satisfação de outras necessidades. A vida do trabalhador se torna, para ele, apenas o meio que lhe permite existir. Em outras palavras, o sujeito humano se torna o objeto de seus próprios produtos.

${ }^{6}$ Deve-se desvendar os mecanismos a partir dos quais a burguesia reserva uma educação necessariamente precária aos filhos da classe trabalhadora é essencial para mostrar como a escola, por ser um reflexo e não uma causa da sociedade de classes. Snyders mostra o ponto central da sociedade de classes, que é a detenção do capital e dos meios de produção por uma classe servindo-se da exploração de outras, trabalhando a questão da educação e da cultura. "A escola confunde-se com uma instituição de reprodução da cultura legítima e desta forma para a ordem estabelecida” (p. 77). Para ele escola tem um papel importante, acomodar desde cedo os trabalhadores ao seu papel de explorados na sociedade, impregná-los dos valores da burguesia para impedir que se organizem politicamente contra o sistema que os explora cotidianamente, encher suas cabeças de preconceitos e mistificações. Sua função efetiva consiste em provocar o fracasso das crianças proletárias para finalmente as sujeitar aos seus postos de exploradas" (p. 78). O Manifesto do Partido Comunistaconsiste em um rico diagnóstico conjuntural da época, denunciando a irracionalidade da ordem capitalista e suas consequências para a humanidade, desvelando o reino da burguesia, construído a partir da exploração do trabalho alheio. Por outro lado este documento histórico não deve ser analisado como um catecismo, com leis rígidas, mas deve ser analisado como um documento datado, como expressão de um momento histórico, conforme seus autores alertam no Prefácio à Edição Alemã de 1872. Contrapondo-se aos socialistas utópicos, Marx e Engels consideram que a abolição da sociedade burguesa deve ser realizada em sua totalidade e não em determinadas regiões ou setores isolados, muito menos através de uma mudança paulatina, pela reforma: Quando os antagonismos de classes, no interior das nações, tiverem desaparecido, desaparecerá a hostilidade e entre as próprias nações (MPC, p.36). Exige-se o engajamento efetivo de toda a classe operária. A linha teórico-metodológica do materialismo histórico, é o fio condutor de seu conteúdo, ou seja, que a produção material é o pressuposto para as transformações políticas e sociais de uma época e que toda a história tem sido uma história das lutas de classes, entre explorados e exploradores, opressores e oprimidos. A publicação do Manifesto, produziu impacto político nas relações entre as classes sociais. Podemos afirmar que a história nuca foi a mesma depois desta obra. A classe operária, organizada em um partido revolucionária, deverá destruir o Estado burguês, devendo organizar um novo Estado, denominado ditadura do proletariado, capaz de suprimir a propriedade privada dos meios de produção.

Recebido em: $\quad 18 / 12 / 10$

Aprovado em: $10 / 02 / 11$ 